\title{
O papel da espiritualidade/religiosidade no fenômeno da drogadicção: uma revisão integrativa de literatura
}

\section{The role of spirituality/religiosity in the phenomenon of drug addiction: an integrative review of literature}

\author{
Mary Rute Gomes Esperandio* \\ Márcia Regina Corrêa**
}

Resumo: Este estudo tem como objetivo apontar o papel da espiritualidade/religiosidade no fenômeno da drogadicção. O método utilizado foi a revisão integrativa, com levantamento nos Periódicos da CAPES; SciELO e BVS. Após o exame dos 281 trabalhos capturados, 39 estudos empíricos foram selecionados para análise, sendo categorizados em dois grandes temas: "epidemiologia" e "tratamento". Os estudos foram desenvolvidos, predominantemente, na área da Saúde. A maioria, 69,2\%, focaliza questōes epidemiológicas. 30,7\% abordam os processos de reabilitação. Os resultados indicam que a espiritualidade/religiosidade funciona como fator protetivo, preventivo e/ou curativo (tratamento). Sugere-se que sejam desenvolvidas pesquisas longitudinais e em perspectiva interdisciplinar, aproveitando-se de contribuiçôes específicas da Bioética, Psicologia da Religião e Teologia Prática, visando à investigação dos mecanismos de ação da espiritualidade/religiosidade no contexto da drogadicçáo.

Palavras-Chave: Dependência Química; Espiritualidade/Religiosidade; Bioética; Psicologia da Religião; Teologia Prática.

Abstract: This study aims to point out the role of spirituality/religiosity in the drug addiction situation. The method used was the integrative review, with a survey at CAPES Periodicals; SciELO and VHL. After examining the 281 collected studies, 39 empirical works were selected for analysis. They were categorized into two major themes: "epidemiology" and "treatment". The studies were developed predominantly in the area of Health Sciences. The majority, 69.2\%, focuses on epidemiological issues. $30.7 \%$ deal with rehabilitation processes. The results indicate that spirituality/religiosity works as a protective, preventive and/or healing factor (treatment). It is suggested that longitudinal and interdisciplinary researches should be developed considering specific contributions from Bioethics, Psychology of Religion and Practical Theology, in order to investigate the mechanisms of action of spirituality/religiosity in the context of drug addiction.

* Psicóloga. Doutora em Teologia com pós-doutorado em Psicologia da Religião. Professora Adjunta no Programa de Pós-Graduação em Teologia e no Programa de Pós-Graduação em Bioética na Pontifícia Universidade Católica do Paraná (PUC-PR). Contato: mary.esperandio@pucpr.br

** Graduada em Teologia. Mestre em Teologia pela Pontifícia Universidade Católica do Paraná (PUC-PR). Professora na Escola Bíblica Senhor Bom Jesus de Araquari. Contato: marciajerusalem@gmail.com 
Keywords: Chemical Dependency; Spirituality/Religiosity; Bioethics, Psychology of Religion, Practical Theology

\section{Introduçáo}

O termo drogadicção é uma junção das palavras: droga e adicção. Na Medicina, a palavra "droga" refere-se a qualquer substância com o potencial de prevenir ou curar doenças, aumentar o bem-estar físico ou mental. Na Farmacologia, refere-se a agentes químicos que alteram os processos bioquímicos e fisiológicos (SENAD, 2010, p. 57). O termo "adicção", por sua vez, refere-se à inclinação ou apego de alguém por alguma coisa, ou o uso continuado de uma substância que resulta na alteração de humor ou comportamento, apesar das consequências adversas de dependência, ou comprometimento neurológico (Kalina, 1999, p.24). Assim, temos a palavra drogadicção significando, segundo Kalina (1999, p. 20), a conduta de uma pessoa que perdeu a noção da realidade, comprometendo seu funcionamento mental. Na Psiquiatria, este fenômeno é caracterizado no DSM V (Sigla em inglês para Manual Diagnóstico e Estatístico de Transtornos Mentais) como Transtorno de Dependência Química, uma doença crônica, multifatorial (diversos fatores contribuem para o seu desenvolvimento), classificada como um transtorno psiquiátrico (American Psychiatric Association, 2014).

Percebe-se, pois, que o Transtorno de Dependência Química, ou a Drogadicção, deixa de ser algo circunscrito ao âmbito meramente individual e se estabelece também como um problema social e de Saúde Pública. O comprometimento mental advindo da drogadicção desdobra-se em condutas psicossociais disfuncionais, decorrendo daí uma série de outros problemas, destacando-se as mais diversas formas de violência.

O tratamento da drogadicção foi, por muito tempo, uma preocupação quase exclusivamente religiosa. As Casas de Recuperação/Comunidades Terapêuticas, assentadas em filosofia e métodos religiosos de tratamento, nasceram como iniciativas de igrejas e de pessoas religiosas. Mas a compreensão da dependência química como doença crônica parece ter aberto espaço para outras formas de tratamento e a Psicologia passou a questionar a eficácia das formas religiosas no manejo da drogadicção. Contudo, a crítica dos Conselhos de Psicologia em relação às Comunidades Terapêuticas são mais amplas e têm procedência, uma vez que há, na atualidade, um número expressivo de Comunidades Terapêuticas para 
tratamento da dependência química assentadas em filosofias diversas e não apenas com base em tratamentos religiosos, sendo que em muitas delas observou-se a violação dos direitos humanos, conforme relatório do Conselho Federal de Psicologia. O Conselho Federal de Psicologia manifestou-se publicamente como contrário ao funcionamento de Comunidades Terapêuticas no modo como proposto na Resolução 29, de 30 de junho de 2011. Tal documento, "RDC no 29”, prevê em seu Artigo 1º, Parágrafo Único, que o “principal instrumento terapêutico a ser utilizado para o tratamento das pessoas com transtornos decorrentes de uso, abuso ou dependência de substâncias psicoativas deverá ser a convivência entre os pares” (Ministério da Saúde, RDC 29, 2011).

Considerando que muitas comunidades terapêuticas, mesmo as não religiosasconfessionais têm como proposta filosófica de tratamento a integração da espiritualidade, é mais que pertinente a pergunta sobre o papel da religião e da espiritualidade no fenômeno da dependência química. Assim, o presente estudo tem como objetivo apresentar os resultados de uma revisão integrativa de literatura sobre esse tema.

\section{Metodologia}

O presente estudo utiliza como método a revisão integrativa de literatura. Este tipo de investigação tem sido largamente utilizado no campo da saúde, principalmente nas análises das práticas-baseadas-em-evidência. A revisão integrativa de literatura diz respeito ao estudo que "inclui a análise de pesquisas relevantes que dão suporte para a tomada de decisão e a melhoria da prática clínica, possibilitando a síntese do estado do conhecimento de um determinado assunto, além de apontar lacunas do conhecimento que precisam ser preenchidas com a realização de novos estudos” (Mendes, Silveira, Galvão, 2008, p. 759).

A pergunta norteadora desta pesquisa foi relativa ao papel da religiáo e da espiritualidade/religiosidade no fenômeno da dependência química, tanto no que diz respeito às questóes epidemiológicas, que abordam os fatores de risco do uso e abuso de substâncias psicoativas (proteção e prevenção), quanto em relação às questôes de tratamento ou manutenção da abstinência. Para tanto, fez-se um levantamento da publicação existente no período entre 1980 e 2015, com atualização do levantamento dos dados em dezembro de 2016. As bases de dados consultadas foram os Periódicos da CAPES (Coordenação de Aperfeiçoamento de 
Pessoal de Nível Superior); SciELO (Scientific Eletronic Library) e a BVS (Biblioteca Virtual de Saúde). Os termos de busca foram: "Religião e Drogas"; "Espiritualidade e Drogas"; "Religiosidade e Drogas"; "Religião e Dependência Química”; "Espiritualidade e Dependência Química”; "Religiosidade e Dependência Química"; "Comunidades Terapêuticas e Religião"; "Comunidade Terapêutica e Religiosidade"; "Comunidade Terapêutica e Espiritualidade"; "Comunidade Terapêutica”.

$\mathrm{Na}$ utilização dos termos de busca acima mencionados e suas variadas combinaçóes, a primeira busca resultou na captura de 281 trabalhos. Com exceção de dois trabalhos em língua inglesa, os outros 279 foram publicados em língua portuguesa. Os dois trabalhos em inglês que compuseram a amostra foram conduzidos no Brasil e publicados em revistas nacionais. Nas bases de dados pesquisadas, 167 trabalhos são originários da ScIELO; 95 da BVS e 19 do Portal de Periódicos da CAPES.

Após uma análise mais minuciosa, foram descartados os trabalhos que não se relacionavam diretamente com o tema, as repetiçóes de estudos nas bases pesquisadas (incluindo aqui, as teses e/ou dissertaçóes que se transformaram em artigos), e os estudos caracterizados como ensaios e/ou de revisão de literatura, resultando, assim, numa seleção de 39 estudos empíricos a serem analisados.

\section{Resultados}

Os estudos foram publicados, predominantemente, nas áreas das Ciências da Saúde, distribuídos da seguinte forma: Saúde Pública: nove estudos; Psicologia: sete estudos, Psiquiatria: seis estudos; Saúde Coletiva: cinco estudos; Educação e Serviço Social: três estudos em cada área; Medicina e Enfermagem: dois estudos em cada área; Ciências Sociais e Ciências Biológicas: um estudo cada área. As pesquisas foram conduzidas, principalmente, no Estado de São Paulo, onde foram realizados 22 estudos, compondo $56 \%$ da amostra. A maior parte das pesquisas, $66,7 \%$, é de natureza quantitativa e 33,3\% de natureza qualitativa. A distribuição mais detalhada dos estudos está apresentada na Tabela 1. Embora o levantamento tenha compreendido o período entre 1980 e 2015, as publicaçóes em português, nas bases pesquisadas, iniciam-se a partir de 1992, sendo que em toda a década de 1990, apenas dois trabalhos relacionados ao tema foram publicados. Os outros 37 estudos foram publicados a partir de 2004. 
Tabela 1: Distribuição da Publicação: Ano, Área de Conhecimento e Tipo de Estudo.

\begin{tabular}{|c|c|c|c|c|}
\hline $\begin{array}{c}\text { Ano da } \\
\text { Publicaçáo }\end{array}$ & $\begin{array}{l}\text { Quantidade } \\
\text { de Estudos }\end{array}$ & Área do Conhecimento & $\begin{array}{c}\text { Local de } \\
\text { Realizaçáo }\end{array}$ & Natureza do Estudo \\
\hline 1992 & 1 & Saúde Pública & SP & Quantitativo \\
\hline 1999 & $\overline{1}$ & Medicina & $\mathrm{SP}$ & Quantitativo \\
\hline \multirow{3}{*}{2004} & \multirow{3}{*}{3} & Saúde coletiva & $\mathrm{RJ}$ & Qualitativo \\
\hline & & Psiquiatria & SP & Quantitativo \\
\hline & & Psiquiatria & ES & Quantitativo \\
\hline 2005 & 1 & Psiquiatria & $\mathrm{SP}$ & Quantitativo \\
\hline \multirow{2}{*}{2006} & \multirow{2}{*}{2} & Saúde Pública & $\overline{\mathrm{SP}}$ & Quantitativo \\
\hline & & Educação & SP & Quantitativo \\
\hline \multirow{3}{*}{2007} & \multirow{3}{*}{3} & Medicina & $\mathrm{SP}$ & Quantitativo \\
\hline & & Saúde Pública & SP & Quantitativo \\
\hline & & Psiquiatria & $\mathrm{SP}$ & Quantitativo \\
\hline \multirow{9}{*}{2008} & \multirow{9}{*}{9} & Saúde Pública & $\mathrm{SP}$ & Quantitativo \\
\hline & & Saúde Pública & SP & Qualitativo \\
\hline & & Psicologia & SP & Quantitativo \\
\hline & & Psicologia & SP & Qualitativo \\
\hline & & Psicologia & SP & Qualitativo \\
\hline & & Psicologia & RS & Quantitativo \\
\hline & & Psicologia & MG & Quantitativo \\
\hline & & Enfermagem & SP & Quantitativo \\
\hline & & Educação & SP & Quantitativo \\
\hline \multirow{2}{*}{2009} & \multirow{2}{*}{2} & Saúde Pública & $\overline{P E}$ & Quantitativo \\
\hline & & Educação & $\mathrm{PR}$ & Quantitativo \\
\hline \multirow{2}{*}{2010} & \multirow{2}{*}{2} & Saúde Coletiva & $\mathrm{SP}$ & Qualitativo \\
\hline & & Saúde Coletiva & BA & Quantitativo \\
\hline \multirow{5}{*}{2011} & \multirow{5}{*}{5} & Ciências Sociais & $\overline{\mathrm{RJ}}$ & Quantitativo \\
\hline & & Saúde Coletiva & MG & Quantitativo \\
\hline & & Serviço Social & RJ & Qualitativo \\
\hline & & Serviço Social & RJ & Qualitativo \\
\hline & & Serviço Social & RJ & Qualitativo \\
\hline \multirow{3}{*}{2012} & \multirow{3}{*}{3} & Saúde Pública e Ciências da Religião & $\overline{\mathrm{RJ}}$ & Qualitativo \\
\hline & & Enfermagem & SC & Quantitativo \\
\hline & & Saúde Pública & RJ & Quantitativo \\
\hline \multirow{2}{*}{2013} & \multirow{2}{*}{2} & Ciências Biológicas e Sociais & $\overline{S P}$ & Quantitativo \\
\hline & & Psiquiatria & RJ & Quantitativo \\
\hline \multirow{2}{*}{2014} & \multirow{2}{*}{2} & Psicologia & $\mathrm{SP}$ & Qualitativo \\
\hline & & Saúde Coletiva & BA & Quantitativo \\
\hline \multirow{3}{*}{2015} & \multirow{3}{*}{3} & Psiquiatria & $\overline{\mathrm{RS}}$ & Quantitativo \\
\hline & & Saúde Pública & $\mathrm{RJ}$ & Qualitativo \\
\hline & & Psicologia & SP & Qualitativo \\
\hline Total & 39 & & & \\
\hline
\end{tabular}


Os 39 trabalhos selecionados para análise podem ser organizados em duas grandes categorias: "Prevalência da religiáo nos estudos sobre consumo de drogas" e "Espiritualidade/Religiosidade e Processos de Reabilitaçáo de pessoas com problemas de dependência química”.

O uso do binômio espiritualidade/religiosidade náo significa a tomada destes dois termos como sinônimos. Pelo contrário, trata-se de dois termos distintos, mas que podem se sobrepor. Entende-se, neste trabalho, a espiritualidade em sentido mais amplo que religiosidade. A espiritualidade pode abarcar a religiosidade, mas isto não é condição necessária. A espiritualidade deriva da dimensão espiritual do humano. Em sentido psicológico, trata-se da dimensão onde se assenta a busca pelas perguntas existenciais de propósito e sentido da vida. Em sentido teológico, espiritualidade diz respeito ao que toma o indivíduo como "preocupação última", "aquilo que o toca incondicionalmente", como nos informa o teólogo Paul Tillich (1980, p. 5) ao abordar a dinâmica da fé. Este teólogo destaca que aquilo que toca o ser humano incondicionalmente, diferenciando-o dos demais seres vivos, são as "preocupaçóes espirituais". Tillich esclarece que as preocupaçóes espirituais tanto incluem questóes próprias da vida, tais como bem-estar, saúde e vida, família, valores cognitivos e estéticos, justiça e humanidade, como também as ultrapassam. Configura-se, desse modo, o que ele denomina como "preocupação última", ou seja, aquilo que toma o ser humano incondicionalmente (Tillich, 1980, p. 06).

As considerações desse teólogo convergem com a definição de espiritualidade assumida na Conferência de Consenso, de 2009, nos Estados Unidos, quando esta foi definida, no campo dos cuidados em saúde, como referindo-se "ao modo como os indivíduos buscam e expressam sentido e propósito e o modo como se experiência conexão com o momento, consigo mesmo, com os outros, com a natureza e com o transcendente ou sagrado" (Puchalski et al., 2009, p. 887). É nesse sentido, portanto, que a religiosidade pode ser uma expressão da espiritualidade do indivíduo. A religiosidade expressa-se, via de regra, através do envolvimento em atividades específicas como orações, novenas, frequência a missas e cultos, e o engajamento em atividades diversas pautadas por preceitos e tradiçóes institucionais confessionais. Em geral, “o sujeito religioso assume certas crenças, práticas e valores ético-morais ligados a uma religião instituída” (Esperandio, 2014, p. 808). Assim, o binômio espiritualidade/religiosidade usado neste trabalho compreende esses aspectos, sem preocupar-se em estabelecer uma distinção de quando um ou outro sentido é enfatizado. 
Os estudos sobre consumo de drogas e a prevalência da religiâo: fator protetivo ${ }^{1} e$ preventivo $^{2}$

Há um número significativo de estudos, 27 (ou seja, 69,2\%) entre os 39 selecionados para análise, que, ao abordar o consumo de substâncias psicoativas, pesquisaram também a variável religiáo como um importante aspecto a ser considerado nesse contexto. É importante destacar que vários estudos náo tinham como objetivo central verificar a relação entre consumo de drogas e religião, mas, sim, verificar os fatores de riscos envolvidos no consumo de drogas (início e/ou uso pesado); a caracterização do estilo de vida; a educação familiar; o contexto socioeconômico; e o padrão de uso. Os pesquisadores que acrescentaram a variável “religiâo", principalmente através de questôes como o envolvimento em atividades religiosas, importância da religião na vida do indivíduo, educação religiosa na infância, e não simplesmente se tinham ou não uma religião, encontraram que a religiáo aparece como fator protetivo e preventivo do consumo e/ou uso nocivo de drogas. Muitos desses estudos foram conduzidos junto a estudantes de Ensino Médio e universitários. Por exemplo, Carvalho e Cotrin (1992), conduziram uma pesquisa junto a 16.117 estudantes do Ensino Fundamental e Ensino Médio em 15 cidades do Brasil para verificar se a prática de atividades extracurriculares poderia ser preventiva do consumo de drogas e álcool. Os autores buscaram evidência sobre a ideia corrente de que jovens "desocupados" ficam mais expostos ao consumo disfuncional de drogas. Os autores observaram que "na grande maioria dos casos, nenhuma associação foi encontrada entre prática de esportes, atividades comunitárias e artísticas e o consumo de álcool e outras drogas" (Carvalho, Cotrin, 1992, p. 992). Contudo, afirmam os autores, "observou-se, com frequência, correlação negativa fraca entre o uso de álcool (11 cidades) e drogas (6 cidades) e a prática de atividades religiosas" (Carvalho, Cotrin, 1992, p. 992), sendo que os protestantes tradicionais e pentecostais foram os que apresentaram correlaçóes negativas de maior intensidade. Diante desses resultados, os autores concluíram que a religião é protetora do consumo de drogas, sobretudo, por seus códigos morais, e que é importante pensar em como ocupar o tempo de maneira que o jovem se realize em suas potencialidades.

Percepção semelhante a respeito do efeito protetor e preventivo de formas de expressão religiosa mais restritivas são apresentadas em outros estudos, tais como os

\footnotetext{
${ }^{1}$ Fator protetivo diz respeito a manter algo ou alguém seguro contra perigo, dano ou perda.

${ }^{2}$ Fator preventivo diz respeito a impedir/prevenir alguma coisa de acontecer ou impedir/prevenir alguém de fazer alguma coisa.
} 
de Dalgalarrondo et al. (2004; 2005); Silva et al. (2006); Cruz (2006); Barros et al. (2007); Almeida (2008); Martins et al. (2008); Amato et al. (2008); Bezerra et al. (2009); Dallo (2009) e Fernandes (2011).

$\mathrm{O}$ estudo de Amato et al. (2008) junto a 371 pacientes entre 18-85 anos, atendidos no âmbito da atenção primária à saúde em Juiz de Fora, mostra que a religião dos participantes foi significativa para o padrão de consumo de bebida. $\mathrm{O}$ menor percentual de pessoas suscetíveis ao risco de álcool foi entre os evangélicos, $7 \%$. Os católicos apresentaram um índice três vezes maior, $21 \%$, e os sem religiáo quatro vezes mais, 31\%. O estudo de Bastos; Bertoni e Hacker (2008, p. 14), com amostra nacional (coletada em 2005) entre 5.040 pessoas de ambos os sexos, na faixa etária de 16 a 65 anos, encontrou que indivíduos cuja principal atividade de lazer eram atividades culturais, esportivas e religiosas apresentaram $73,3 \%$ menos chances de consumir drogas do que os frequentadores de festas, bares e boates.

Em uma amostra coletada junto a 4.210 estudantes do ensino médio da rede pública no Estado de Pernambuco por Bezerra et al. (2009), os pesquisadores verificaram que os adolescentes que se declararam "evangélicos" apresentaram risco de exposição ao consumo de bebidas alcoólicas $72 \%$ inferior em comparação àqueles que declararam não ter religião, sendo que os que reportaram ser "praticantes", independentemente da afiliação religiosa, o risco de exposição ao consumo de bebidas alcoólicas foi 29\% inferior (Bezerra et al., 2009, p. 443).

Uma amostra menor, no Paraná, coletada junto a 133 alunos do Ensino Médio, confirma que entre os indivíduos engajados em formas de expressão religiosa mais conservadoras é menor o índice de consumo de álcool. Os estudantes evangélicos destacaram-se no consumo controlado do álcool, sendo apenas 7,7\%, enquanto que os católicos foram 39\%, os sem religião 47\%, e aqueles que pertencem a outras religiōes foram 57\% (Dallo, 2009, p. 59-60).

Ou seja, formas mais restritivas de religião parecem ter um efeito protetor contra as drogas em função dos códigos morais que o indivíduo internaliza. Observação semelhante é feita por Abdala et al. (2010, p. 95) ao afirmar que, quando o indivíduo adere a uma denominaçáo religiosa, ele adere a um conjunto de valores, símbolos, comportamentos e práticas sociais, a um amplo e complexo ethos religioso que inclui, entre outras coisas, a aceitaçáo do ou a recusa ao uso de álcool e drogas. Abdala et al., em estudo junto a 233 estudantes de vários cursos das Faculdades Adventistas da Bahia, apontaram que a religiosidade/espiritualidade tem uma contribuição positiva na abstinência, redução e/ou abandono do uso e abuso de substâncias psicoativas. O estudo de Abdala et al. mostrou que 79,8\% dos estudantes reportaram forte convicção de que as crenças ajudam na abstinência de drogas e 
$90,4 \%$ creem que o fator religiosidade/espiritualidade ajuda no abandono ou redução do uso de drogas.

Há vários estudos cujos resultados sugerem que indivíduos que receberam educação religiosa na infância são menos propensos ao uso de álcool e drogas, conforme mostram os estudos de Soldera e Dalgalarrondo (1999); Sanchez, Oliveira e Nappo (2004); Bastos; Bertoni e Hacker (2008).

Outros fatores de risco se mostram facilitadores do uso de bebidas alcoólicas, tais como "ser do sexo masculino, estar concluindo o ensino médio no período noturno e não ter religião", conforme mostra o estudo de Martins et al. (2008, p. 314) junto a 1.227 estudantes do Ensino Médio em duas escolas públicas do país e de Cruz (2008). O estudo de Pavani et al. (2007), com dados de uma amostra entre 1.041 estudantes de Ensino Médio em São José do Rio Preto, SP, apresenta resultados semelhantes: as maiores taxas de consumo de maconha foram encontradas nos estudantes do sexo masculino que estudavam no período noturno, bem como no grupo daqueles que não possuíam religião ou não eram praticantes.

Entre os vários estudos sobre os fatores de risco relacionados ao consumo de drogas, a maioria de natureza quantitativa, destaca-se o estudo qualitativo de Sanchez, Oliveira e Nappo (2004) que apresenta resultados de entrevistas em profundidade realizadas junto a 62 jovens de baixo poder aquisitivo, usuários e não usuários de drogas. Os pesquisadores observaram que "a estrutura familiar, a religiosidade, a disponibilidade de informaçóes acerca da dependência e suas consequências e o estabelecimento de perspectivas de futuro foram relatadas como os fatores protetores mais importantes" (Sanchez, Oliveira, Nappo, 2004, p. 53). Chamou a atenção, porém, dos pesquisadores, o papel desempenhado pela espiritualidade e religiosidade dos entrevistados. Para eles, “a espiritualidade apresentou-se desperta em todos os entrevistados náo-usuários que, através do desinteresse pelo consumo de drogas e suas implicaçóes, mostraram uma preocupação quanto à manutenção de seu bem-estar e auto-preservação, atribuída principalmente ao fato de estabelecerem planos de futuro em sua vida" (Sanchez, Oliveira e Nappo, 2004, p. 54). Aos pesquisadores pareceu que a espiritualidade dos entrevistados estava intimamente associada com a religiosidade, já que a maior parte dos entrevistados desse grupo acreditava e praticava uma determinada religião.

Quanto ao papel da informação como medida preventiva do uso de drogas entre jovens em situação de risco, Sanchez et al. (2010, p. 704) observaram, em seu estudo qualitativo junto a 32 não-usuários e 30 usuários, que "a família aparece como importante fonte de divulgação de informação, além da experiência pessoal do 
entrevistado (decorrente da observação direta dos efeitos negativos da droga sobre a comunidade, familiares e amigos), da influência da religião, mídia, escola e amizades”.

Os estudos sobre fatores de risco e padrão de consumo de drogas foram realizados não apenas entre jovens em situações de vulnerabilidade. Um estudo entre 275 estudantes de graduação do Curso de Ciências da Saúde buscou verificar os padróes de policonsumo simultâneo de drogas e suas implicaçôes de gênero, sociais e legais entre estudantes universitários (Nóbrega et al., 2012). Também junto a essa população, a religião se mostrou como fator protetor. Os 30,2\% de estudantes que não consumiram substâncias psicoativas consideravam a religião muito importante. Julgar a religião menos importante ou não importante representou, segundo os autores, um fator que influenciava o consumo. $\mathrm{O}$ estudo evidenciou, também, que algumas situaçóes levam ao uso do álcool: o estresse, o excesso de trabalhos da graduação, e o lidar com a dor e o sofrimento dos outros (Nóbrega et al., 2012, p.33). Um outro estudo entre 268 estudantes graduandos dos Cursos de Ciências Biológicas e Sociais com o objetivo de verificar os fatores de risco para o consumo de drogas (Silva, Santos et al., 2013) encontrou que 60\% dos estudantes do primeiro ano e $67 \%$ dos estudantes do quarto ano declararam que tinham religião. Estes estudantes haviam feito uso de droga uma vez na vida, levando os pesquisadores à conclusão de que a ausência de crença religiosa não deveria ser identificada como um fator de risco. Contudo, os dados levantados mostram que foi verificado exclusivamente se os participantes eram ou não adeptos de alguma religião. Sabe-se que, no Brasil, a maioria da população reporta ter uma religião, ainda que não seja praticante da mesma. O estudo de Silva, Nogueira et al. (2013), realizado entre 100 estudantes de Enfermagem de Minas Gerais e que buscou avaliar o consumo de álcool e de outras drogas e investigar a relação entre esse consumo e o bem-estar espiritual e as características sociodemográficas/religiosas dos estudantes, chegou a achados que levantam questóes sobre a relação entre religiosidade, espiritualidade e uso nocivo de drogas. Nesse estudo, ao utilizar a variável religião, os autores utilizaram, entre outros instrumentos, a Escala de Bem-Estar Espiritual, de Paloutzian. Os autores buscaram, ainda, coletar dados sobre a prática religiosa dos participantes; tempo de prática religiosa; importância da religião; prática religiosa familiar e importância da religiosidade na formação do profissional de saúde (Silva, Nogueira et al., 2013, p. 193). Os dados levantados pelos pesquisadores demonstrou o álcool como a substância mais utilizada pelos estudantes (84\%) e levou-os a concluir que

A espiritualidade pode influenciar positivamente no uso de substâncias psicoativas entre estudantes universitários, uma vez que escores negativos de bem-estar espiritual [OR: 3,325; IC95\%: 1,059-10,441] e ausência de prática religiosa 
frequente [OR: 3,392; IC95\%: 1,064-10,811] estiveram associados a maior uso disfuncional, especialmente de álcool, considerado uma droga socialmente aceita (Silva, Nogueira et al., 2013, p. 193).

Os autores sugerem como iniciativas preventivas ao consumo de drogas psicoativas, atividade vinculadas a práticas espirituais, tanto "em nível individual e comunitário", quanto "na universidade, de forma que os estudantes possam utilizar a própria espiritualidade como estratégia para a manutenção da saúde, para que posteriormente possam usar esse recurso em sua atuação profissional" (Silva, Nogueira et al., 2013, p. 193).

Para verificar o bem-estar psicológico e fatores associados a ele, Souza et al. (2012) conduziram uma pesquisa junto à população de 1.621 jovens entre 18-24 anos da cidade de Pelotas, RS. Os participantes da pesquisa foram recrutados aleatoriamente por sorteio, com coleta em domicílio, com vistas a avaliar os fatores associados ao bem-estar psicológico. Os resultados sugeriram bem-estar psicológico relacionado à religiáo. Dos entrevistados, 85,3\% apresentaram bem-estar psicológico relacionado aos seguintes fatores: não uso de substâncias ilícitas, trabalho remunerado, prática da religião, em classes socioeconômicas $\mathrm{A}$ e $\mathrm{B}$, com alta escolaridade e náo presença de transtornos psiquiátricos. $\mathrm{O}$ estudo constatou ainda, segundo os autores, "associação entre bem-estar psicológico com baixo nível socioeconômico e baixa escolaridade, indicando que os jovens de classes sociais menos favorecidas apresentam menores índices de bem-estar psicológico" (Souza et al., 2012, p. 1172). Ainda em Pelotas, Narvaez et al. (2015) buscaram avaliar junto a 1.560 jovens entre 18-24 anos, a relação entre o uso de crack e as dimensóes da qualidade de vida e funcionamento social. O instrumento utilizado para coleta foi o Alcohol, Smoking and Substance Involvement Screening Test. O estudo apontou que o uso do crack foi associado a qualidade de vida pobre, pior funcionamento, resultados acadêmicos prejudicados e envolvimento religioso mais baixo. Aliados a esses fatores, a presença da mãe e ausência do pai ficaram mais pronunciadas nos usuários de crack, sendo os mais prováveis de buscar tratamento psicológico e psiquiátrico do que a população geral (Narvaez et al., 2015, p. 214).

Outro estudo com objetivo de caracterizar a iniciação e o padrão de consumo de substâncias psicoativas, entre 475 adolescentes e adultos jovens matriculados em Centro de Atenção Psicossocial Álcool e Drogas - CAPS AD, foi o de Silva et al. (2014). Para a coleta de dados, os pesquisadores utilizaram os registros dos atendimentos do período entre 2003 e 2008. Os autores apontam que a maioria dos atendidos era do sexo masculino, solteiros, com baixa escolaridade, coabitando com 
pais, apresentavam sintomas psíquicos e não tinham religião (Silva et al., 2014, p. 739).

O único trabalho que afirma não ter encontrado relação entre possuir uma religiáo e menor consumo de álcool e outras drogas foi o de Campos et al. (2011), que buscou verificar o padrão de consumo de álcool entre estudantes do Ensino Médio de uma cidade de Minas Gerais. O estudo coletou amostras entre 1.967 adolescentes de instituiçóes públicas e privadas de ensino, utilizando o questionário AUDIT (do inglês Alcohol Use Disorder Identification Test, em português "Teste de Identificação de Distúrbio de Uso do Álcool”).

Ressalta-se, contudo, a própria observação dos pesquisadores de que este achado talvez tenha se contraposto às várias outras pesquisas, em razão de que foi levantado se o participante possuía ou não uma religião, e não se era, necessariamente, praticante da mesma (Campos et al., 2011, p. 4751).

\section{Espiritualidade/Religiosidade e os Processos de Reabilitação de Pessoas com Problemas de Dependência Química}

Nessa categoria foram encontrados 12 estudos (30,7\%), sendo que o ano de 2004 marca o início de tais publicaçóes. Nove deles referem-se à modalidade de tratamento realizado em Comunidades Terapêuticas (Silva e Garcia, 2004; Raupp e Milnitisky-Sapiro, 2008; Jesus e Rezende, 2008; Marques, 2011; Barreto, 2011; Dimarães, 2011; Scaduto, Barbieri e Santos, 2014; Ribeiro e Minayo, 2015; Scaduto, Barbieri e Santos, 2015). As Comunidades Terapêuticas (CT) pesquisadas localizam-se em Porto Alegre, Rio de Janeiro e no Estado do Amazonas.

Dois estudos abordam o processo de reabilitação em distintas formas de expressão religiosa (Sanchez e Nappo, 2008; Rocha, Guimarães e Cunha, 2012), e um outro estudo explora os aspectos motivacionais de pessoas em processos de recuperação da drogadicção em distintas propostas de tratamento: Alcoólicos Anônimos (AA), Centro de Atenção Psicossocial Álcool/Drogas (CAPS ad) e Comunidades Terapêuticas (Gonçalves, 2008).

As Comunidades Terapêuticas (CT) como Modalidade de Tratamento da Dependência Química

O primeiro estudo publicado sobre CT, capturado nas bases de dados utilizadas nesta revisão, data de 2004. Trata-se de um estudo no campo da Psiquiatria, conduzido por Silva e Garcia (2004), no qual os autores buscaram avaliar as 
características das comunidades terapêuticas religiosas (CTR) que trabalham com dependentes químicos no Espírito Santo (ES). Os autores identificaram 22 CTR e, em visita institucional, aplicaram um instrumento com 19 questôes. Os pesquisadores apontaram o predomínio de CTR vinculadas às religióes protestantes tradicionais (54,5\%), criadas a partir da década de 1990 (45,5\%), onde as atividades propostas envolvem os aspectos espiritual, ocupacional, recreativo e físico e visam à ocupação do tempo do paciente. $\mathrm{O}$ tempo médio de internação é de sete a nove meses, com predominância de atendimento a pessoas do sexo masculino (91\%). O tratamento é feito por técnicos treinados em práticas de aconselhamento. Para os autores, o caráter ideológico presente nas CTR pesquisadas aponta a conversão religiosa como saída eficaz da condição de dor e sofrimento.

Ainda sobre a abordagem religiosa como tratamento da dependência química, o estudo de Ribeiro e Minayo (2015) analisou o papel das CT religiosas no complexo de favelas de Manguinhos, Rio de Janeiro. Para levantamento de dados, as pesquisadoras utilizaram-se de materiais institucionais, entrevistas e observação participante em atividades religiosas como "cultos, missas e outras celebraçôes, momentos de trabalho social e do cotidiano institucional" (Ribeiro, Minayo, 2015, p. 518). As autoras apontam que as principais formas de recuperação e de reabilitação são a evangelização e a conversão religiosa.

Embora o estudo seja sobre CT religiosas, o mesmo não menciona quantas e/ou quais foram as CT visitadas. Os dados foram levantados a partir de entrevistas com três pessoas convertidas à religião, com histórico de dependência de drogas e envolvimento com o tráfico de entorpecentes; cinco líderes religiosos, quatro entrevistas individuais e dois grupos de três e seis pessoas - coordenadores de serviços sociais prestados por entidades religiosas (Ribeiro e Minayo, 2015, p. 518). As pesquisadoras informam que "participaram do estudo 14 igrejas e associaçóes religiosas entre católica, evangélicas e espíritas, entre 2010 e 2012” (Ribeiro, Minayo, 2015, p. 518).

Segundo as autoras, as CT confessionais concebem um modelo de tratamento centrado na oração e na abstinência, e observam que este modelo de tratamento está em desacordo com as políticas públicas de saúde mental, porém "os equipamentos públicos não têm conseguido dar respostas eficazes à demanda” (Ribeiro, Minayo, 2015, p. 515).

Três dissertaçóes de mestrado sobre uma mesma CT, denominada "Comunidade Terapêutica Fazenda da Esperança”, de confissão religiosa católica, localizada no Amazonas, abordam as mudanças de comportamento por ela promovidas (Marques, 2011), os motivos que levam seus egressos ao retorno do uso disfuncional de drogas 
(Barreto, 2011) e o atendimento emergencial de residentes dessa CT (Dimarães, 2011). Os três estudos são de natureza qualitativa. Marques (2011) entrevista três ex-residentes e conclui que o período de tratamento aponta resultados positivos no que tange à proposta da Comunidade Terapêutica. Barreto (2011) entrevistou 5 egressos e 6 famílias com vistas à compreensão do processo de recaída. A autora conclui que as recaídas são vistas como normais para alguns, necessária para outros, e fazem parte do processo de recuperação. A família tem importante participação em tal processo e sua implicação em todas as etapas da reabilitação é fundamental. Dimarães (2011) apresenta um estudo de caso para discutir as possibilidades de recuperação do residente. Para a autora, tal possibilidade depende do próprio sujeito, uma vez que a experiência oferecida pela CT oferece subsídios para o retorno à sociedade, à família e ao trabalho, e devolvendo ao indivíduo direitos dos quais fora excluído em função do uso indevido de drogas e /ou álcool, resgatando a cidadania e abrindo horizontes para a construção de um novo projeto de vida (Dimarães, 2011).

Os estudos de Scaduto, Barbieri e Santos (2014; 2015) analisaram tanto as mudanças no funcionamento psicológico de internos de uma CT quanto sua vinculação aos princípios da mesma e sua relação com o processo de mudança vivenciado ao longo do tratamento. A CT pesquisada, localizada no interior de São Paulo, oferece um tratamento religioso-cristão sem se ater a qualquer confissão religiosa particular, mas incentiva o desenvolvimento da espiritualidade através de atividades religiosas e da prática do exercício espiritual contido nos 12 Passos dos Alcoólicos Anônimos (AA). Os autores realizaram entrevistas com sete homens que se submeteram ao tratamento na CT investigada e os avaliou a partir do Inventário Multifásico Minnesota de Personalidade (Improved Readability Form - MMPI-IRF) e Teste de Apercepção Temática (TAT). Os resultados apontam, segundo os pesquisadores, que o tratamento promoveu melhoras no funcionamento psicológico em graus diferentes para os participantes, em termos do tipo de estruturação da personalidade. Para os autores, a personalidade pareceu mediar a qualidade da introjeção das experiências afetivas ao longo do tratamento. Ao avaliarem o vínculo dos participantes aos princípios da CT, os autores observaram que aqueles que se vincularam aos princípios de mudança pessoal propostos apresentaram mudanças mais expressivas do que aqueles que aderiram apenas aos princípios morais e religiosos. Neste sentido, o tratamento na CT investigada promove, segundo os autores, melhoras no funcionamento psicológico em diferentes graus, dependendo do nível de integração dos recursos da personalidade de seus internos. 
Um outro estudo sobre a modalidade de tratamento em CT, de cunho etnográfico e de análise de conteúdo, foi conduzido por Raupp e Milnitisky-Sapiro (2008) em uma CT feminina, na cidade de Porto Alegre, RS. Os autores concluem, com base nos resultados, que há uma "defasagem entre o prescrito pelas políticas públicas e a realidade da comunidade terapêutica pesquisada, a qual, apesar de proporcionar acolhimento às adolescentes, dificulta o desenvolvimento de suas singularidades e potencialidades devido à ênfase no 'modelo moral' de tratamento da drogadição" (Raupp, Milnitisky-Sapiro, 2008, p. 361).

Jesus e Rezende (2008) analisam a experiência dos dirigentes de instituiçóes que dão assistência a dependentes de drogas no Vale do Paraíba, em São Paulo. Os autores entrevistam dez dirigentes de instituiçóes de assistência à dependência química e observam que há carência tanto de profissionais especializados e de equipes interdisciplinares da área de saúde quanto falta planejamento e funcionamento das instituiçóes. $\mathrm{O}$ estudo aponta a "presença de atividades de cunho religioso pautadas pelo discurso de ajuda ao próximo e a valorização de tarefas direcionadas ao trabalho, a disciplina e a espiritualidade" (Jesus, Rezende, 2008, p. 499). Os autores destacam ainda, a ausência, em todas as instituiçóes pesquisadas, de um protocolo de avaliação (e seguimento) dos resultados do tratamento, e a necessidade de formação específica para a realização do trabalho na área da reabilitação da dependência química.

Estudos com enfoque nos Processos Religiosos de Reabilitação da Dependência Química

O estudo de Rocha, Guimarães e Cunha (2012) focaliza o processo de recuperação do uso indevido de drogas vivido por fiéis de igrejas pentecostais Assembleia de Deus de uma comunidade popular da cidade do Rio de Janeiro. As autoras se utilizaram de entrevistas semiestruturadas e observação participante nas reunióes promovidas pela igreja para as pessoas em recuperação. Foram entrevistados dez homens que buscaram o local como forma de solucionar os problemas relacionados ao uso indevido de drogas. A metodologia de análise de conteúdo apontou que o processo de recuperação envolve elementos totalizantes (subordinação dos fiéis à sua visão de mundo e às suas regras morais, por um lado, e por outro, de oferta de apoio social pela igreja) e individualizantes (aumento da autoestima ligado à descoberta de novas potencialidades e à valorização que recebe do grupoo religioso). Por parte da igreja, percebe-se que a motivação reside na promoção da transformação ("salvação") desses indivíduos. Sua esfera de atuação não está na problemática social e estrutural, mas no indivíduo. 
Quanto à motivação dos sujeitos que elegeram a igreja como local para sua recuperação, as autoras observam que esta alternativa se apresenta, talvez, como a primeira e única, dentro de seu campo de possibilidades, e que para estes homens, em particular, havia coerência entre sua visão de mundo e a da instituição. Além da associação a um grupo respeitado na comunidade onde vivem, para alguns deles, ameaçados pelo tráfico, isto representou a garantia de sua própria sobrevivência.

O estudo de Sanchez e Nappo (2008), realizado em São Paulo, em 2004-2005, também foi de natureza qualitativa, com o uso de entrevistas em profundidade junto a 85 pessoas que haviam utilizado recursos religiosos de tratamento e se encontravam abstêmias. As autoras recrutaram pessoas ligadas a distintos grupos religiosos: católicos, evangélicos e espíritas. Os resultados apontam diferenças no suporte à pessoa dependente de drogas em cada grupo. As pesquisadoras observaram ainda que os evangélicos foram os que mais utilizaram a religião como forma exclusiva de tratamento, apresentando repulsa ao papel do médico e a qualquer tipo de tratamento farmacológico. Já os espíritas foram os que buscaram mais apoio terapêutico à dependência de álcool, simultaneamente ao tratamento convencional. Para as autoras, isto se justifica em razão de seu maior poder aquisitivo. Os católicos utilizaram mais a terapêutica religiosa exclusiva, mas relataram menos repulsa a um possível tratamento médico. Nos três grupos religiosos, o método de coping mais empregado foi a oração, sendo utilizada, ainda, como "método ansiolítico". O estudo aponta que atividades como confissáo e perdão, penitências, e/ou conversão, funcionam como formas de reestruturação da vida e de aumento da autoestima. Para participantes do estudo, para além da fé religiosa, o que os manteve na abstinência do consumo de drogas "foi o suporte, a pressáo positiva e o acolhimento recebido no grupo, e a oferta de reestruturação da vida com o apoio incondicional dos líderes religiosos" (Sanchez, Nappo, 2008, p. 265).

Gonçalves (2008) buscou avaliar a relaçáo entre espiritualidade e os níveis motivacionais dos indivíduos em processo de recuperação, tanto na modalidade de participação em Grupos de Mútua Ajuda, quanto em CAPS e CT (confessionais ou não). A autora utilizou como instrumento para coleta dos dados a Spirituality Self Rating Scale (SSRS), um questionário para levantamento dos dados sociodemográficos e a Escalas de Motivação e Espiritualidade - URICA. A amostra foi constituída de 138 (69\%) de indivíduos do sexo masculino, provindos de diferentes formas de tratamento: participantes de um grupo de AA, um serviço de CAPS-ad e três Comunidades Terapêuticas (evangélica, católica e uma terceira sem vinculação religiosa). A média de idade dos participantes da pesquisa foi de 39 anos, sendo 71 deles católicos (51,4\%), 38 (27,5\%) evangélicos, e 83 deles (60,1\%) reportaram ser 
praticantes da religião (Gonçalvez, 2008, p. 58). Não houve relação estatística significante entre espiritualidade (conforme levantada pelas escalas utilizadas) e aspectos da vida religiosa dos indivíduos, e a maioria, 84 (60,8\%), faz diferenciaçáo entre espiritualidade e religiosidade. $\mathrm{O}$ estudo mostrou que os estágios motivacionais que apresentaram relação com espiritualidade foram a pré-contemplação, a ação e a manutenção. Para a autora, é necessário haver sucessivas avaliações dos processos que envolvem os aspectos da espiritualidade no contexto do tratamento e motivação na mudança de comportamentos, com vistas a facilitar a promoção de novos estilos de vida menos vulneráveis à recaídas.

\section{Discussão: Contribuiçóes da Bioética, Teologia e da Psicologia da Religiáo em algumas questóes relacionadas ao fenômeno da drogadicçáo}

O levantamento da literatura produzida no Brasil sobre o papel da religiosidade/ espiritualidade no fenômeno da drogadicção indica que a religiosidade/espiritualidade tem "potencial de atuação" protetiva e preventiva do uso disfuncional de drogas, sobretudo na fase da adolescência e juventude. Como evidenciam os estudos aqui listados, tal "potencial de atuação" é colocado em funcionamento se mediado pelo envolvimento do indivíduo em atividades religiosas. Ou seja, uma "afirmação de pertencimento" a uma dada confissão (seja ela qual for), cuja prática pessoal esteja desvinculada de seu caráter identitário, em outras palavras, "pertencer sem efetivamente ser", não produz efeito significativo sobre o indivíduo em relação aos riscos e/ou padráo de consumo da droga. A correlação positiva entre religiáo e o não uso de drogas, sendo a religião um fator preventivo ou protetivo depende, pois, da internalização pessoal de crenças religiosas. Esse dado é comprovado também pelos estudos que apontam que as formas de expressão religiosa mais restritivas são as que mais funcionam como fatores protetivos, uma vez que produzem maior controle comportamental sobre o indivíduo. Já no caso do "potencial curativo" da religiosidade (curativo no sentido de controle do uso nocivo da droga), parece haver uma ligeira ambivalência nos estudos. Isto aponta a necessidade de condução de investigaçóes com metodologias mais rigorosas para levantamento dos dados nos quais se pretende verificar a variável religiosidade/espiritualidade no fenômeno da drogadicção.

A presente revisão mostra que a pesquisa sobre o fenômeno da drogadicção concentra-se muito mais nos fatores de risco, no estilo e padrão de consumo, e na caracterização da população com problemas de dependência química (69.2\% dos estudos), do que em estudos que abordam os tratamentos disponíveis (30.7\%). 
Quanto às questóes que envolvem os fatores de risco e caracterizaçáo da população com problemas de dependência química, os estudos analisados apontam que, além do náo envolvimento em atividades religiosas como um dos fatores que caracterizam os grupos de risco para o consumo de drogas (e/ou uso nocivo de substâncias químicas), podem ser elencados ainda um conjunto de fatores: ser do sexo masculino; ser solteiro; estudar à noite; ter baixa escolaridade; apresentar sintomas psíquicos e coabitar com os pais; não ter tido educaçáo religiosa na infância, apresentar piores escores de bem-estar psicológico e espiritual, e não ter projetos de futuro. Tais fatores, quando combinados, são preditores do uso disfuncional da droga.

A literatura evidencia que as principais formas de tratamento utilizadas são baseadas nos modelos de Comunidade Terapêutica, Grupos de Mútua Ajuda e CAPS. Parece haver na literatura algumas tendências polarizadas no que diz respeito às abordagens de tratamento de cunho religioso, desde análises pouco críticas acerca dos mesmos até uma aparente repulsa a tratamentos que têm a religião como estratégia. Poucos são os trabalhos que buscam uma investigação mais neutra, no sentido de enfocar mais nos efeitos e repercussão do tratamento no sujeito e menos nos pontos de vista pessoais, por vezes preconcebidos, dos próprios investigadores.

Nesse sentido, o encontro interdisciplinar que conjuga Bioética, Teologia Prática e Psicologia da Religião configuram uma interface na promoção da saúde, que em muito podem contribuir na discussão do fenômeno da drogadicção apontando algumas questóes a serem consideradas no estudo desse tema.

A Teologia Prática, ao focalizar o estudo da experiência concreta dos sujeitos, e em especial dos conteúdos daquilo que o sujeito toma como "preocupação última", vai ao encontro da Bioética, nos seus apontamentos sobre vulnerabilidade e autonomia. A Psicologia da Religião, por sua vez, destaca os processos de coping (enfrentamento) religioso/espiritual (Pargament, 1997) presentes nas situaçóes nas quais o sujeito se defronta com problemas de saúde que ameaçam a vida. Em tais experiências, é comum os sujeitos irem em busca de resposta pelo sentido do sofrimento. A droga pode se apresentar ao indivíduo em situação de vulnerabilidade social, econômica e psicológica, como uma alternativa de minimização do sofrimento. Esta é, contudo, uma utilização potencialmente perigosa, que pode levar ao uso nocivo da droga.

Por outro lado, há um volume bastante grande de estudos que mostram que comumente, em situaçóes de sofrimento e vulnerabilidade, o indivíduo busca nas formas de coping religioso/espiritual modos afirmativos da vida no processo de enfrentamento de experiências que às vezes se colocam como "sem sentido". 
Assim, os elementos que permeiam a questão do sentido estão presentes, em suas especificidades, tanto na Teologia Prática quanto na Psicologia da Religião e na Bioética. O médico psiquiatra e fundador da Logoterapia ${ }^{3}$, Viktor Frankl, já observava que o problema da nossa Era é o vazio de sentido (2014, p. 101). Essa mesma afirmação é feita também pelo teólogo Paul Tillich (1976, p. 37). Ambos mostram como a questão do sentido liga-se à espiritualidade. Nesta perspectiva, a observação dos psicólogos americanos Forcehimes e Tonigan (2009, p. 116) é bastante útil para compreender o lugar que a droga ocupa no processo existencial da pessoa com Transtorno de Dependência Química. Estes autores observam que o indivíduo com tal transtorno investe a maior parte de seu tempo existencial e de sua energia emocional e psíquica com questóes ligadas à droga: a vontade de consumo, os meios de obtê-la, os resultados indesejados do uso descontrolado, as várias perdas em todos os âmbitos da existência decorrentes do uso incontrolável da substância etc. Neste sentido, a droga, para a pessoa que tem a doença crônica da dependência, toma o lugar de "preocupação última", usando as palavras do teólogo Tillich. Ela passa a ser aquilo que "toca o sujeito incondicionalmente", uma vez que todas as outras questôes existenciais ficam em segundo plano, "condicionadas", pois, às implicações geradas pelo uso disfuncional da droga. A droga passa, assim, a ocupar o lugar central na existência do indivíduo. A drogadicção resulta em um modo de existência no qual o sujeito aliena-se de si mesmo, isolando-se, ainda, das relaçóes significativas com outros. Aliado a isso, o indivíduo passa a ter sua capacidade criativa e de trabalho produtivo reduzidas, com consequências também para os planos assistenciais governamentais. Assim, pode-se compreender que o Transtorno de Dependência Química tem, de fato, impacto na dimensão espiritual do indivíduo, incluindo sua capacidade decisória, colocando-o em posição de vulnerabilidade, face às limitaçôes de sua autonomia. A partir dessa perspectiva, faz sentido o discurso das pessoas em recuperação (normalmente ligadas a Grupos de Mútua Ajuda e Programas religiosos), afirmando a adicção como um problema de natureza espiritual, cuja saída seria, justamente, a partir do enfoque na espiritualidade como forma de cura/tratamento.

Há que se destacar, todavia, que pessoas recorrem a drogas por diversos motivos, conforme constata-se na literatura examinada neste estudo. Neste sentido, não se pode desconsiderar os diferentes tipos de usuários, de circunstâncias de uso, padróes de consumo, e, consequentemente, de efeitos de uso. Em outras palavras, os padróes de uso que não afetam o quadro fisiológico e psíquico do usuário de maneira

\footnotetext{
${ }^{3}$ Escola Psicoterápica que enfoca o sentido existencial do indivíduo e a dimensão espiritual da existência.
} 
significativa não terão impacto no potencial autônomo e decisório do indivíduo. A Bioética, como campo de conhecimento que reflete sobre a ética aplicada às ciências da vida em geral e na área da saúde, em particular, contribui com a discussão do tema ao reforçar duas noçóes caras a esse campo: vulnerabilidade e autonomia.

Em relação à vulnerabilidade, a Bioética chama a atenção para o fato de que, sendo de origens diversas os elementos que configuram uma situação de vulnerabilidade (trabalho, situaçóes econômicas e sociais, doença, tempo, e outras mais), faz-se necessário compreender o fenômeno do consumo de psicotrópicos para além da vulnerabilidade (apontada nos fatores de risco). Neste sentido, o princípio bioético da autonomia ajuda-nos a lembrar as tendências paternalistas e autoritárias no trato dessas questóes. Há momentos em que o indivíduo perde sua autonomia decisória em função do padrão de uso, colocando-o em posição de desvantagem em relação aos demais, aumentando, assim, suas condiçóes de vulnerabilidade. Isto, entretanto, não pode obnubilar o fato de que as razóes e as motivaçóes que levam ao consumo da droga precisam ser avaliadas à luz da autonomia do indivíduo: sua liberdade e capacidade de decisão pelo uso. Incluem-se nestas considerações, também as decisóes pelo tipo de tratamento para aqueles que dele necessitam. Futuros estudos sobre essa temática serão enriquecidos ao tomarem em conta esses aspectos bioéticos que são facilmente deixados de lado na abordagem do tema.

\section{Conclusão}

O presente estudo mostra que é ainda relativamente pequena a produçáo teórica relacionada à temática da drogadicção, principalmente sobre as questóes ligadas ao seu tratamento, havendo maior concentração nos estudos sobre os fatores de risco e padrão de consumo.

A espiritualidade/religiosidade aparece nos estudos como uma variável que joga um papel importante no fenômeno da drogadicçáo, quer como fator protetivo, preventivo ou curativo (no sentido de tratamento). Neste sentido, a investigaçáo empírica, baseada em evidências, já tem mostrado de modo suficiente a relação, via de regra, mais positiva do que negativa da espiritualidade/religiosidade no contexto do fenômeno estudado. Assim, para o avanço dos estudos, os futuros trabalhos têm o desafio de investigar não mais se a espiritualidade/religiosidade tem influência neste contexto, mas de que modo essa variável funciona, qual o seu alcance, sob quais condiçóes os resultados são mais positivos. Esse tipo de pesquisa poderia ser, por exemplo, sobre o coping (enfrentamento) religioso/espiritual, conflitos espirituais, 
religiosidade intrínseca e extrínseca, e como estes vários fatores atuam nos processos de recuperação e/ou recaída das pessoas com Transtorno de Dependência Química. Além disso, faz-se relevante investigar, também, o modo como indivíduos autodeclarados ateus lidam com problemas relacionados à drogadicção, quais suas estratégias específicas de coping e como estas diferem, em eficácia, em relação a estratégias religiosas de enfrentamento. Tais estudos poderiam apontar com mais precisão, o papel protetor da religião, sobretudo em comparação com outros sistemas de crença (humanistas e seculares) e outras visões de mundo ${ }^{4}$.

A pesquisa sobre o fenômeno da drogadicção está concentrada em algumas áreas, como a Saúde Pública, Psicologia, Psiquiatria e Saúde Coletiva, sendo a maioria de corte transversal (dados coletados em um único momento) e aponta a necessidade de estudos longitudinais que explorem os mecanismos de ação da espiritualidade/religiosidade.

Considerando a importância da religiosidade no contexto cultural brasileiro, o aprofundamento deste tema seria de grande relevância para a Saúde Pública e para as várias ciências que de algum modo se ocupam dos aspectos éticos no campo da saúde. Sugere-se ainda que as pesquisas tenham em seu horizonte a perspectiva interdisciplinar, em especial as consideraçóes teórico-práticas desenvolvidas na Bioética, Psicologia e Teologia, que em muito podem contribuir com os futuros estudos sobre o tema.

\section{Referências}

ABDALA, Gina Andrade, RIOS, Mino Correia; TORRES, Amilton; RODRIGUES, Wellington Gil; BRASIL, Mágela de Souza. A Religiosidade/ Espiritualidade como influência positiva na abstinência, redução ou abandono do uso. Revista de Estudos de Religião, São Paulo, v. 1, 2010, pp. 77-98.

ALMEIDA, Eliane Sartorello. O julgamento sociomoral de universitários usuários de maconha. Dissertação (Mestrado em Educação). Universidade Estadual Paulista, Marília/SP, 2008.

AMATO, Castro Tatiana; SILVEIRA, Pollyanna Santos; OLIVEIRA, Jussara Siqueira; RONZANI, Telmo Mota. Uso de bebida alcoólica, Religião e outras características sócio demográficas em pacientes de atenção primária à saúde - Juiz de

\footnotetext{
${ }^{4}$ A sugestão aqui apresentada sobre a necessidade de estudos comparativos entre indivíduos autodeclarados ateus e indivíduos religiosos e as estratégias de coping por eles utilizadas foi uma generosidade do/a parecerista do artigo. Registramos aqui o nosso agradecimento.
} 
Fora - MG - Brasil - 2006. Revista Eletrônica Salud Mental, Alcool y Drogas, Ribeirão Preto, v. 4, ISS2, 2008, pp. 01-17.

AMERICAN PSYCHIATRIC ASSOCIATION (2014). Manual diagnóstico e estatístico de transtornos mentais (DSM-V) $5^{a}$ edição. Porto Alegre: Artmed.

BARRETO, Maria Izolda de Oliveira. Egressos da Fazenda da Esperança de Manaus: Recaída, por quê? Dissertação (Mestrado). Pontifícia Universidade Católica do Rio de Janeiro, Rio de Janeiro, 2011.

BARROS, Marilisa Berti de Azevedo; BOTEGA, Neury José; DALGALARRONDO, Paulo; MARÍN-LEÓN Letícia; OLIVEIRA, Helenice Bosco de. Prevalência da dependência de álcool e fatores associados em estudos de base populacional. Revista de Saúde Pública, São Paulo, v. 41, n. 04 2007, pp. 502-509.

BASTOS, Francisco; BERTONI, Neilane; HACKER, Mariana A. Consumo de álcool e drogas: principais achados de pesquisa de âmbito nacional, Brasil 2005. Revista de Saúde Pública, v. 42, 2008, pp. 109-117.

BEZERRA, Jorge; BARROS, Mauro Virgílio Gomes; TENÓRIO, Maria Cecília Marinho; TASSITANO, Rafael Miranda; BARROS, Simone Storino Honda; HALLAL, Pedro C. Religiosidade, consumo de bebidas alcoólicas e tabagismo em adolescentes. Revista Panamericana de Salud Pública, v. 26, n. 5, 2009, pp. 440-447.

CAMPOS, Juliana Alvares Duarte Bonini; ALMEIDA, Jussara de Castro, GARCIA, Patrícia Petromili Nordi Sasso, e FARIA, João Bosco. Consumo de álcool entre estudantes do ensino médio do Munícipio de Passos - MG. Revista Ciência e Saúde Coletiva, v. 16, n. 12, 2011 , pp. 4745-4754 (10).

CARVAlHO, Vera Aparecida V.; COTRIM, Beatriz Carlini. Atividades extracurriculares e prevenção ao abuso de drogas: uma questão polêmica. Revista de Saúde Pública, v. 26, n. 03, 1992, pp. 145-149.

CRUZ, Luciana A. N. Uso de álcool e julgamento sócio moral de estudantes do ensino médio. Dissertação (Mestrado em Educação). Universidade Estadual Paulista, São Paulo, 2006.

DALGALARRONDO, Paulo; CORREAA, Filho Heleno Rodrigues; SOLDERA, Meire Aparecida; SILVA, Cleide Aparecida M.. Jovens Pentecostais e espíritas em comparação a católicos: uso de álcool e droga e saúde mental. Jornal Brasileiro de Psiquiatria, v. 54, n. 03, 2005, pp. 182-190. 
DALGALARRONDO, Paulo; SOLDERA, Meire Aparecida; CORREAA, Filho Heleno Rodrigues; SILVA, Cleide Aparecida M.. Religião e uso de drogas por adolescentes. Revista Brasileira de Psiquiatria, v. 26, n. 02, 2004, pp. 82-90.

DALLO, Luana. Padrão de uso de álcool e outras drogas entre estudantes de Cascavell PR. Dissertação (Mestrado). Universidade Estadual Paulista, São Paulo, 2009.

DIMARÁES, Carla C. de S.; SILVA, Ilda L. R. da. Atendimento emergencial dos residentes na Fazenda da Esperança: uma experiência de retorno à vida. Dissertaçáo (Mestrado). Pontifícia Universidade Católica do Rio de Janeiro, Rio de Janeiro, 2011.

ESPERANDIO, Mary Rute Gomes. Teologia e a pesquisa sobre espiritualidade e saúde: um estudo piloto entre profissionais da saúde e pastoralistas. Revista Horizonte, v.12, n. 35, 2014, pp. 805-832.

FERNANDES, Sílvia R. A. Marcos definidos da condição juvenil para católicos e pentecostais na baixada fluminense - algumas proposiçóes a partir de um survey. Revista Religiáo e Sociedade, v. 31, n. 01, 2011, p. 96-125.

FORCEHIMES, Alyssa e TONIGAN, J. Scott. Spirituality and Substance Use Disorders. In.: HUGUELET, Philippe; KOENIG, Harold (ed.). Religion and Spirituality in Psychiatry. New York: Cambridge University Press, 2009, pp. 114127.

FRANKL, Viktor. A presença ignorada de Deus. 15a ed. São Leopoldo: Sinodal; Petrópolis: Vozes, 2007/2014.

GONÇALVEZ, Angélica M. de Souza. Estudos dos níveis motivacionais em relação ao uso de substâncias psicoativas e a espiritualidade. Dissertação (Mestrado em Enfermagem Psiquiátrica). Universidade do Estado de São Paulo, Ribeirão Preto/SP, 2008.

JESUS, Cláudia Fabiana; REZENDE, Manuel Morgado. Dirigentes de instituições que assistem dependentes químicos no Vale do Paraíba. Estudos de Psicologia de Campinas, v. 25, n. 04, 2008, pp. 499-507.

KALINA, Eduardo. Drogadicção: individuo, familia e sociedade. $3^{\mathrm{a}}$ ed. Rio de Janeiro: Francisco Alves, 1999.

MARTINS, Raul Aragão; MAZATTO, Antônio José; CRUZ, Luciana Nogueira; POIATE, Suzy Mary Granzoto; SCARIN, Ana Carla Cividanes Furlan. AUDIT para identificação do consumo de álcool entre estudantes do Ensino Médio. Revista Interamericana de psicologia, v. 42, n. 02, 2008, pp. 307-316. 
MARQUES, Jaqueline Lopes. A Fazenda da Esperança do Amazonas e o olhar do exresidente. Dissertação (Mestrado em Serviço Social). Pontifícia Universidade Católica do Rio de Janeiro, Rio de Janeiro, 2011.

MENDES, Karina Dal Sasso; SILVEIRA, Renata Cristina de Campos Pereira; GALVAO, Cristina Maria. Revisáo integrativa: método de pesquisa para a incorporação de evidências na saúde e na enfermagem. Texto contexto - enfermagem, v. 17, n. 04, 2008, pp. 758-764.

MINISTÉRIO DA SAÚDE. Agência Nacional de Vigilância Sanitária (ANVISA). Resolução - RDC no 29, de 30 de junho de 2011. Brasília, D.F. Disponível em: http://bvsms.saude.gov.br/bvs/saudelegis/anvisa/2011/res0029_30_06_2011.html.

Acesso em: 1 mar. 2017.

NARVAEZ , Joana C.M.; PECHANSKY, Flávio; JANSEN, Karen; PINHEIRO, Ricardo T.; SILVA, Ricardo A.; KAPCZINSKI, Flávio; MAGALHÁES, Pedro V. Quality of life, social functioning, family structure, and treatment history associated with crack cocaine use in youth from the general population. Revista Brasileira de Psiquiatria, v. 37, n. 03, 2015, pp. 211-218.

NÓBREGA, Maria do Perpétuo Socorro de Sousa; SIMICH, Laura; STRIKE, Carol; BRANDS, Bruna; GIESBRECHT, Norman; KHENTI, Akwatu. Policonsumo simultâneo de drogas entre estudantes de graduação da área de ciências da saúde de uma universidade: implicaçóes de gênero, sociais e legais, Santo André/Brasil. Texto contexto - enfermagem, v. 21, n. (esp.), 2012, pp. 25-33.

PARGAMENT, Kenneth I. The psychology of religion and coping: Theory, research, practice. New York, USA: The Guilford Press, 1997.

PAVANI Rafael Augusto Borges; SILVA, Elissandro de Freitas; MORAES, Maria Silvia; CHIARAVALLOTI NETO, Francisco. Caracterização do consumo de maconha entre escolares do ensino médio de São José do Rio Preto, SP, 2003, Brasil. Revista Brasileira de Epidemiologia, v. 10, n. 02, 2007, pp. 157-167.

PUCHALSKY, Christina; FERRELL, Betty; VIRANI, Rose; OTIS-GREEN, Shirley; BAIRD, Pamela; BULL, Janet; CHOCHINOV, Harvey; HANDZO, George; NELSON-BECKER, Holly; PRINCE-PAUL, Maryjo; PUGLIESE, Karen; SULMASY, Daniel. Improving the Quality of Spiritual Care as a Dimension of Palliative Care: The Report of the Consensus Conference. Journal of Palliative Medicine, v. 12, n. 10, 2009, pp. 885-904.

RAUPP, Luciane Marques; MILNITISKY-SAPIRO, Clary. A reeducação de adolescentes em uma comunidade terapêutica: $\mathrm{O}$ tratamento da drogadicçáo em uma instituição religiosa. Psicologia: Teoria e Pesquisa, v. 24, n. 03, 2008, pp. 361-368. 
RIBEIRO, Fernanda Mendes Lages; MINAYO, Maria Cecília de Souza. As Comunidades Terapêuticas religiosas na recuperação de dependentes de drogas: o caso de Manguinhos, RJ, Brasil. Interface (Botucatu), v. 19, n. 54, 2015, pp. 515526.

ROCHA, Mary Lança Alves; GUIMARÁES, Maria Beatriz Lisboa; CUNHA, Marize Bastos. O processo de recuperação do uso indevido de drogas em igrejas pentecostais Assembleia de Deus. Interface - Comunicação, Saúde e Educação, v. 16, n. 40, 2012, pp. 177-190.

SANCHEZ, Zila Van der Meer; NAPPO, Solange Aparecida. Intervenção religiosa na recuperação de dependentes de drogas. Revista de Saúde Pública, v. 42, n. 02, 2008, pp. 265-272.

SANCHEZ, Zila Van der Meer; OLIVEIRA, Lúcio Garcia.; NAPPO, Solange Aparecida. Fatores protetores de adolescentes contra o uso de drogas com ênfase na religiosidade. Revista Ciência e Saúde Coletiva, v. 09, n. 01, 2004, pp. 43-54.

SANCHEZ, Zila Van der Meer; OLIVEIRA, Lúcio Garcia; RIBEIRO, Luciana Abeid; NAPPO, Solange Aparecida. O papel da informação como medida preventiva do uso de drogas entre jovens em situação de risco. Revista Ciência e Saúde Coletiva, v. 74(5), n. 03, 2010, pp. 699-708.

SCADUTO, Alessandro Antonio; BARBIERI, Valéria; SANTOS, Manoel Antônio. Comunidades terapêuticas para dependentes de substâncias psicoativas: avaliação dos resultados do tratamento. Revista Psicologia: Teoria e Prática, v. 16, n. 02, 2014, pp. $156-171$.

SCADUTO, Alessandro Antonio; BARBIERI, Valéria; SANTOS, Manoel Antônio. Adesão aos Princípios da Comunidade Terapêutica e Processo de Mudança ao Longo do Tratamento. Psicologia Ciência e Profissão, v. 35 n. 03, 2015, pp. 781-796.

SENAD - Secretaria Nacional de Políticas sobre Drogas. (2ª ed.) Glossário de Álcool e Drogas. Brasília: Secretaria Nacional de Políticas sobre Drogas/Gabinete de Segurança Institucional. 2010. Disponível em: http://www.campinas.sp.gov.br/governo/assistencia-social-segurancaalimentar/prevencao-as-drogas/glossario.pdf. Acesso em: 17 jan. 2016

SILVA, Leonardo V. E. Rueda; MALBERGIER, André; STEMPLIUK, Vladimir de Andrade; ANDRADE, Arthur Guerra. Fatores associados ao consumo de álcool e drogas entre estudantes universitários. Revista de Saúde Pública, v. 40, 2006, n. 02, pp. 280-288. 
SILVA, Carolina Carvalho; COSTA, Maria Conceição Oliveira; CARVALHO, Rosely Cabral de; AMARAL, Magali Teresópolis Reis; CRUZ, Nilma Lázara de Almeida; SILVA, Mariana Rocha da. Iniciação e consumo de substâncias psicoativas entre adolescentes e adultos jovens de Centro de Atenção Psicossocial Antidrogas/ CAPS-AD. Revista Ciência e Saúde Coletiva, v. 19, n. 03, 2014, pp. 737-745.

SILVA, Roberta de Paiva; NOGUEIRA, Denismar Alves; SOUZA, Priscila de; MOREIRA, Denis da Silva; CHAVES, Erika de Cássia Lopes. Relação entre bemestar espiritual, características sociodemográficas e consumo de álcool e outras drogas por estudantes. Jornal Brasileiro de Psiquiatria, v. 62, n. 03, 2013, pp. 191-198.

SILVA, Meire Luci; SANTOS, Nathalia M. R.; BARNABÉ, Viviani; SILVA, Vítor E. Valenti. Fatores de risco que podem induzir o uso de drogas por estudantes de uma Universidade Pública. Revista Brasileira de Crescimento e Desenvolvimento Humano, v. 23, n. 03, 2013, pp. 01-06.

SILVA, Jacirley de Almeida; GARCIA, Maria Lúcia Teixeira. Comunidade Terapêutica religiosa no tratamento da dependência química no Estado do Espírito Santo. Jornal Brasileiro de Psiquiatria, v. 53, n. 04, 2004, pp. 243-252.

SOLDERA, Meire Aparecida; DALGALARRONDO, Paulo. Religião e uso frequente de drogas por estudantes de segundo grau. Medicina Ribeiráo Preto, v.32, (supl), 1999: pp. 09-12.

SOUZA, Luciano Dias de Mattos; MARAGALHONI, Tauana da Costa; QUINCOSES, Maiara Tavares; JANSEN, Karen; CRUZEIRO, Ana Luara Sica; ORES, Liliane; SILVA, Ricardo Azevedo; PINHEIRO, Ricardo Tavares. Bem-estar psicológico de jovens de 18 a 24 anos: fatores associados. Caderno Saúde Pública, v. 28, n. 06, 2012, pp. 1167-1174.

TILLICH Paul. A coragem de ser. Rio de Janeiro: Paz e Terra, 1976.

TILLICH Paul. Dinâmica da Fé. 2a ed. São Leopoldo: Sinodal, 1980.

Recebido: 27/06/2017

Aprovado: 21/08/2017 